\title{
Sustainable Development in Healthcare Facilities. Case Study: Swedish and Greek Hospital
}

\author{
Konstantina Tsioumpri ${ }^{1}$, Georgia Tsakni ${ }^{1}$ \& Aspasia Goula ${ }^{1}$ \\ ${ }^{1}$ Master of Health and Social Care Management, University of West Attica, Athens, Greece \\ Correspondence: Konstantina Tsioumpri, Master of Health and Social Care Management, University of West \\ Attica, Athens, Greece. Tel: 30-69-4610-8388. E-mail: ktsioumpri@yahoo.com
}

Received: June 29, 2020

doi:10.5539/jsd.v13n4p178
Accepted: July 20, $2020 \quad$ Online Published: July 29, 2020

URL: https://doi.org/10.5539/jsd.v13n4p178

\begin{abstract}
In the past few years sustainable development has been in the center of attention among organizations around the world. The literature focuses mostly on the industry sector for its negative impact on the environment. However, a cautious study reveals that the healthcare sector similarly contributes to the climate change with a negative effect. The purpose of this study aims to analyze the ways (actions and plans) in which sustainable development is incorporated between a Greek and a Swedish healthcare facility. Relevant global literature and data were utilized together with the environmental reports of the two hospitals. In addition, a combined survey (interviews and quantitative research) was completed at the Greek facility to draw conclusions on the personnel's knowledge and habits regarding sustainable development. The results highlighted the necessity to achieve sustainable development and the manner in which it has to be integrated into healthcare. Furthermore, the differences in actions that follow both the Greek and the Swedish hospital are pointed out, as well as similarities, with solutions adapted to the reality of its country individually. The outcome highlighted the significance of accomplishing sustainability in healthcare as well as in any other organization. Additionally, there are a lot of opportunities for improvement towards this goal. Solutions to various issues and possible ways of improvement are proposed, while the need for a new research at Greek national level is highlighted, so that sustainability actions can be adjusted to the Greek reality in the healthcare field.
\end{abstract}

Keywords: environment, environmental management systems, healthcare facilities, hospital, sustainability, sustainable development

\section{Introduction}

Sustainable development is defined as "the development that meets the needs of the present without compromising the ability of future generations to meet their own needs" (United Nations, 1987, pp 24). The healthcare sector has a key role in managing health problems that arise from climate change, whereas is simultaneously an important greenhouse gas emission factor both directly and indirectly through the goods and services that uses (Watts et al, 2019). Except for the energy consumed in the form of heating fuels and electricity, the healthcare system also utilizes huge quantities of goods and services, for example pharmaceuticals and medical devices, which require significant energy inputs for their production (Eckelman \& Sherman, 2016).

Elements that incorporate sustainability into a healthcare facility are hospital's design, in which energy efficiency integration ensures long-term positive results (Bardwell, 2007), energy consumption for heating, ventilation, air conditioning, lighting, (Burger, 2012) operation of equipment and consumption of enormous amounts of water (Department of Health, 2011). Another element comprises the hospital transfers that include ambulance transport, public and private transport of workers and users that contribute to CO2 emissions (Mc Gain \& Naylor, 2014). The goods used in hospital units represent the largest contribution to carbon "footprint" in healthcare (UK NHS, 2012). Reducing hospital waste can lead to economic and environmental enhancements. In particular, improvements in waste management procedures can lead to environmental and financial benefits, through the "waste hierarchy" process. That means disposal, recycling, reuse and reduction of waste and finally achievement of total waste avoidance (Finnveden, Johansson, Lind et al, 2005). In addition to the aforementioned, hospitals and care services that incorporate sustainability initiatives benefit other areas, too. Their efforts contribute to a healthier environment, improve the perception of the organization and can help local communities. Furthermore, they assist in reducing operating costs and allow hospitals to direct more resources to patient care (Health Research and 
Educational Trust, 2014).

\subsection{Environmental Management Systems is Healthcare}

An Environmental Management System (EMS) is defined as the part of the overall management system of an organization comprising the necessary organization structure, activities, processes, roles and responsibilities, appropriate practices, processes and resources to address the environmental impact of its products, services or functions (Morrow \& Rondinelli, 2002).

An environmental management system is significantly important for healthcare facilities which emit gases into the atmosphere and produce hazardous and non-hazardous waste that can, if not properly treated, contribute to air, water and soil pollution. Through the implementation of environmental management system, these facilities can not only prevent pollution, but also analyze and possibly cope with the life cycle effects of their products and services. The implementation of an EMS also contributes to more effective compliance with the current regulations, to encouragement of good community, to provision of better healthcare services and to maintenance of competitiveness in this sector (Environment Science Center, 2003).

The adoption of standards such as EMAS, ISO14001 and EC880/92 by healthcare services could be the best solution for better quality internal environmental performance and care. ISO 14001 and EMAS standards focus on the continuous improvement of environmental performance and the most important phases of their implementation are the following: initial environmental review, determination of environmental policy, improvement of environmental planning, implementation, operation with audits and restorative actions and lastly review of the management team (Lizzi et al, 2017).

\subsection{ISO 14001in Healthcare}

The overall objective of ISO 14001 is to support environmental protection and pollution prevention in accordance with other socio-economic needs and to define the requirements that empower an organization to achieve its intended results for the environmental management system (Zoumboulis, Peleka \&Triantafillidis, 2015, Introduction to ISO 14001:2015, 2015). As far as the ISO 14001 is concerned, an organization should address all environmental issues identified with its activities, such as air contamination, water and sewage, waste management, soil contamination, climate change mitigation and resource adaptation and use (Introduction to ISO 14001:2015, 2015). Numerous associations, including hospitals, introduce an Environmental Management System with the aim of obtaining ISO 14001 certification (Chartier et al, 2014).

\subsection{LEED in Healthcare}

The LEED evaluation system was originated by the U.S. Green Buildings Council in order to create green buildings that are sound, highly efficient and cost-saving (Green Business Certification Inc, 2017). The LEED 2009 for healthcare is intended for inpatient and outpatient facilities and provides the possibility of separating a certification application into two phases: design and construction (US Green Building Council Inc., 2010). The development of an exclusively sustainable system that can produce environmentally sustainable healthcare facilities, while improving patient outcomes and prosperity, staff productivity and energy efficiency is considered important (Xuan, 2015).

\subsection{EMAS in Healthcare}

"The EMAS Regulation (Regulation 761/01 EC) is EU scheme implemented by the European Commission since 1993 and it is for the implementation of an Environmental Management System (EMS) by any organization" (Iraldo, Testa \& Frey, 2009). The Eco- Management and Audit Scheme (EMAS) is a comprehensive environmental management system that includes external assessment as well as provision of the pertinent information to the public (Honkasalo, 1998). This Regulation aims to make open data on environmental performance and to give public acknowledgment to companies that make a significant and sustained attempt to improve their performance towards this goal (Biondi \& Frey, 1995).

EMAS is addressed to all organizations, including those in the field of public health and is based on an accurate standard issued by the International Standardization Organization (ISO) ISO 14001. As a consequence, public healthcare organizations and in particular European public health organizations have numerous approaches to implement an environmental sustainability system. However, the aforementioned companies do not appear to apply such standards as the private sector (Chiarini \& Vagnoni, 2016). Although EMAS can offer many advantages for organizations in the hospital sector, its dissemination is low and the outcomes after meetings with environmental managers in EMAS-registered hospitals uncover various issues, such as a high initial effort to create the necessary documents and an absence of information and awareness of staff (Seifert, 2018). 


\subsection{Green Human Resource Management in Healthcare}

Human Resource Management is characterized as "a set of distinct but interrelated activities, functions, and procedures that are directed at attracting, developing, and maintaining (or disposing of) a firm's human resources" (Lado \& Wilson, 1994). The significance of green practices of the human resources management system is fundamental for employee morale and can assist to achieve great benefits, both for the company and for the employee himself (Cherian \& Jacob, 2012). In the health care sector, research has demonstrated that "green recruitment" and environmental education are key factors in the human resource management ecological orientation. Green staff selection is the first step in guiding hospitals to green issues (Alipour \& Sangari, 2019). Healthcare managers need to have more resources to create environmentally friendly initiatives such as recycling, energy efficiency, water preservation, green procurement and sustainable mobility (Mc Gain \& Naylor, 2014).

\subsection{Green Procurement in Healthcare}

Environmental purchasing is defined as the purchasing function's involvement in supply chain management activities in order to facilitate recycling, reuse, and resource reduction (Carter \& Carter, 1998). Most green procurement initiatives in the healthcare sector focus on procurement criteria that diminish explicit environmental risks. These include eliminating the use of mercury and plastics with polyvinyl chloride (PVC), just as replacing toxic chemicals for cleaning, disinfection and sterilization (Rathi et al, 2013). Research in Great Britain and Italy show that British healthcare organizations appear to have a tendency to request by their suppliers to improve environmental performance over time, including the carbon

"footprint". Italian organizations on the other hand, appear to focus mostly on the required laws and guidelines regarding the environment and safety (Chiarini, Opoku \&Vagnoni, 2017).

Results of a relative study in the United Arab Emirates (UAE) showed that the environmental "footprint" criterion and compliance with supplier legislation are considered the most significant aspects (Malik, Abdallah \& Hussain, 2015). In Australia's public health sector, the absence of financial resources is seen as one of the most critical internal challenges of green procurement, which prevents agencies from implementing green supplies (Hoejmose \& Adrien-Kirby, 2012).

\section{Method}

\subsection{Qualitative Method of Research with the Technique of Interviewing}

The General Oncology Hospital of Kifissia "Agioi Anargiroi" (GOHK) consists of two buildings the General Hospital and the Oncology Unit, has 335 beds and about 800 employees. In 2009, hospital's environmental acts were established and approved; those are additionally observed as moves towards sustainability. Interviews were conducted with the Deputy Director of the Technical Service, the Director of an Oncology Clinic, the Head of Protocol, the Head of Clinical Studies Department and the person in charge of personnel's commuting.

\subsection{Quantitative Method of Research Using the Questionnaire Technique}

The research, at the same hospital, took place in September 2019 within the form of a questionnaire and the SPSS method was applied to draw conclusions on the knowledge and habits of employees in sustainable development. The sample was 104 employees from different departments of the hospital. Approval was received from hospital's IRB for both qualitative and quantitative research. Study participants gave orally their informed consent and their anonymity and confidentiality was ensured.

\subsection{Desk Research}

Karolinska University Hospital is a university hospital with approximately 16.000 employees and 1.340 beds. It is a member of the Scandinavian Centre for Sustainable Development in Health Services (Nordic Center for Sustainable Healthcare) (www.karolinska.se, nordicshc.org). The research review utilized the hospital's latest environmental reports of 2017 and 2018 (Miljöredovisning 2017 and Miljöredovisning 2018). Additionally, data were obtained from the hospital's official website.

\section{Results}

The combined method of research has examined the cases of two hospitals in relation to their sustainability actions. The cases of Karolinska University Hospital in Stockholm, Sweden, and General Oncology Hospital of Kifissia "Agioi Anargiroi", Greece, were studied. The two countries have comparable population sizes of around ten (10) million inhabitants; Sweden has 3.5 times larger area than Greece. The Swedish hospital has twenty times the number of employees and almost four times the capacity of beds than the Greek hospital. The sizes of the two facilities are disparate and partially can be considered incomparable. The decision regarding the selection of hospitals based on their intense differences, in order to illustrate their positive practices as an example for 
emulation. In the Greek hospital, quantitative research was carried out in the form of a questionnaire and gave the presented results in Tables 1 and 2.

Table 1. Characteristics of study respondents

\begin{tabular}{|c|c|c|}
\hline$(N=104)$ & $n$ & $\%$ \\
\hline \multicolumn{3}{|l|}{ Highest education level } \\
\hline Secondary level & 36 & 34.6 \\
\hline University/ Technological Institute & 47 & 45.2 \\
\hline MSc & 18 & 17.3 \\
\hline $\mathrm{PhD}$ & 3 & 2.9 \\
\hline \multicolumn{3}{|l|}{ Position } \\
\hline Administrator/ manager & 29 & 27.9 \\
\hline Medical & 24 & 23.1 \\
\hline Nurse & 25 & 24.0 \\
\hline Other & 26 & 25.0 \\
\hline \multicolumn{3}{|l|}{ Position in charge } \\
\hline No & 88 & 84.6 \\
\hline Head of department & 14 & 13.5 \\
\hline Head manager & 2 & 1.9 \\
\hline \multicolumn{3}{|l|}{ Age (years) } \\
\hline $25-30$ & 17 & 16.3 \\
\hline $30-40$ & 13 & 12.5 \\
\hline $40-50$ & 40 & 38.5 \\
\hline $50+$ & 34 & 32.7 \\
\hline \multicolumn{3}{|l|}{ Years in hospital } \\
\hline Less than 2 years & 25 & 24.0 \\
\hline $2-4$ years & 15 & 14.4 \\
\hline 4-10 years & 23 & 22.1 \\
\hline $10+$ years & 41 & 39.4 \\
\hline
\end{tabular}

Table 2. Greek hospital

\begin{tabular}{lcc}
\hline $\begin{array}{l}\text { Employees' attitudes } \\
\text { development }\end{array}$ & information & $\begin{array}{c}\text { sustainable } \\
n\end{array}$ \\
& & \\
\hline Are you familiar with the term "sustainable development"? & 28 & 26.9 \\
Not at all & 29 & 27.9 \\
Slightly & 30 & 28.8 \\
Very & 17 & 16.3 \\
I know exactly the term & & \\
Which elements compose the term in your opinion? & 34 & 24.6 \\
Economy & 67 & 48.6
\end{tabular}


$\begin{array}{ll}\text { Social welfare } & 17\end{array}$

Way of life

In your opinion how much health care facilities contribute to climate change?

Not at all

0

0

Slightly

Very

Extremely

Which of the following contributes more?

Gas emission

Energy consumption

Waste production

Water consumption

Are you aware of any action or sustainable development program that has taken place in a hospital abroad?

Yes

No

Do you recycle at the hospital?

Never

Sometimes

Often

Always

Which of the following you recycle?

Paper

Plastic

Batteries/ lamps

Devices

How do you commute to and from the hospital?

Car/ Motorcycle

Service bus 77

Public transportation

Carpooling

Do you regularly turn off the lights/ air condition or close the windows when you leave the workplace?

Never 3

Seldom

9

8.7

Often

Always

Are you aware with the term "green" procurement?

Yes

No

The following characteristics have emerged from the qualitative method through the interview technique: the Greek hospital has neither developed an environmental department nor has assigned designated personnel responsible for environmental issues. Hospital's sustainability measures are the following; regular plant care, 
irrigation with self-regulating drip pipes to spare water, management of medical waste in accordance with the provisions of the Joint Ministerial Decision. The solid waste management is also in compliance with the terms and states of this Decision. There is an approved Internal Regulation for the Management of Hazardous Medical Wastes. What is more, energy- saving lamps are preferred and all illuminators are regularly maintained. Standard control and adjustment of burners' operation is carried out annually. Natural gas-fired water boilers are operated on the basis of permitted gas emission limits. Packaging containing pressure gases (bottles) are collected by suppliers and reused. Regular maintenance is performed on the hospital vehicles which are assigned with the proper exhaust card according to the national regulations. The old and useless spare parts and machinery are collected, removed from the premises and distributed through Alternative Management Systems. The used batteries are recycled. Damaged mercury pressure meters, lead chests, medical equipment and computer monitors are collected separately by type and delivered for divestment. A reduction of the managing costs from medical waste handling is achieved by taking concrete measures at the various stages of waste management. An action taken is mainly the appropriate separation of medical waste to avoid expensive or inappropriate processing methods. Another measure is related to the programs (alternative management) of recycling paper material, lamps, batteries and recycling of computer printer supplies. These environmental targets have been revised and are to be renewed in 2020. However, there were measures that were not taken; in particular no energy control system was installed in order to manage the operation of air conditioners (automatic shutdown with the departure of users) as envisaged. Telemedicine is used to a small extent; clinical counsel and instructions are provided to a small degree remotely; patients in compliance with General Data Protection Regulation (GDPR) send exam reports via email or contact by telephone the attending physician in order to receive medical guidance. This is the way remote care is exercised mainly in the oncology clinics. In the clinical trials departments, numerous communications are made in the form of video conferencing while a few trainings are carried out digitally. In addition, the digitization of the protocol department has greatly encouraged saving space and paper, however data are not recorded for the quantities saved.

As far as the Swedish hospital is concerned, Karolinska's environmental work is organized with the support of the hospital's management system. Furthermore, the administration is actively working on the continuous improvement of working methods, which is significant for reducing environmental impacts. Apart from the environmental department and responsible coordinator, the hospital has the environmental informants, who undertake the information and support process towards their colleagues and encourage the environmental work of local companies. For the administration of the hospital, preventive work with environmental issues is seen as a way to address growing health problems. The new building situated in Solna is considered to be one of the most environmentally friendly hospitals in the world. The hospital sets annual targets for sustainability and considers achieving them; using the following ways that appear in tables 3-5.

Greek- Swedish hospital comparison

The activities of the two units have the same effect on the environment, as they consume energy 24 hours a day, seven days per week throughout the year. They use environmentally hazardous materials, drugs, chemicals for disinfection and analysis. The two facilities also manage large quantities of household and hazardous medical waste. Each one has chosen various ways and finally manages to achieve sustainable development. The comparison of the results is presented in Tables 3-5 
Table 3. Swedish- Greek hospital comparison

\begin{tabular}{ll}
\hline Sustainable development act & Swedish hospital \\
\hline $\begin{array}{l}\text { Participation in sustainability } \\
\text { organizations }\end{array}$ & $\bullet \begin{array}{l}\text { Member of the Nordic Centre Sustainable } \\
\text { Healthcare (NCSH). }\end{array}$ \\
& $\begin{array}{l}\text { Collaboration with the Region Stockholm } \\
\text { towards sustainability goals. }\end{array}$ \\
& $\bullet \quad \begin{array}{l}\text { Member of the international network Health } \\
\text { Care Without Harm. }\end{array}$ \\
Environmental department & - Environmental department with responsible
\end{tabular}
environmental coordinator.

- Common values for all employees «Responsibility- Holistic perceptionSolidarity ».

- Vision «Patient first».

\begin{abstract}
Environmental certificationenvironmental management systems
\end{abstract}

- ISO14001:2004 certified

- Preparation for ISO14001:2015.

- Solna new building: certified with gold "Miljöbyggnad", (Swedish Green Building environmental ratings system)

- Currently receiving final Gold LEED certification

\section{Greek hospital}

- Member of the national Digital Waste Registry.
- No environmental department.

- No environmental coordinator responsible for monitoring compliance with the environmental plan.

- ISO9001:2015 Blood donation department

- ISO15189:2012 Hematology department

- Hospital was certified with ISO9001:2008 on 2015 for a number of activities. Certification was not renewed.

- Year 2009 environmental goals were set. Year 2020 goals are to be renewed.

decision making processesbudgeting

- Hospital environmental plan incorporated in decision-making processes and budget.

- Annually environmental goals are set and reports are published.
Participation in environmental programmes safe

Environmentally transportations (personnel business transportation)
- Collaboration with Region Stockholm for approval of the annual environmental plan.

- Participation in "PVC FREE BLOOD BAGS" program.

- Use of communication technology instead of travel.

- Web meetings.

- Video links.

- Reduction of air travel and use of train, taxi and transport service whenever possible.
- Use of online training and meetings in clinical trials departments. 
Table 4. Swedish- Greek hospital comparison

\begin{tabular}{|c|c|c|}
\hline Sustainable development act & Swedish hospital & Greek hospital \\
\hline $\begin{array}{l}\text { Patients and } \\
\text { transportation to and from } \\
\text { hospital }\end{array}$ & $\begin{array}{l}\text { - Use of telemedicine and long distance care giving. } \\
\text { - Goals are set to create better mobility solutions } \\
\text { and increase the public transport share. } \\
\text { - Commuter bus between Karolinska Huddinge and } \\
\text { Karolinska Solna. }\end{array}$ & $\begin{array}{l}\text { - Use of telemedicine to a small } \\
\text { extent. } \\
\text { - Home care service } \\
\text { - Available staff shuttle service. } \\
\text { - Minimum contribution of public } \\
\text { transport. } \\
\text { - Public access to the operating list } \\
\text { and to booking appointments } \\
\text { through internet }\end{array}$ \\
\hline Antibiotics prescription & $\begin{array}{l}\text { - Compulsory training of the personnel prescribing } \\
\text { drugs. } \\
\text { - Reduction in antibiotics prescriptions. }\end{array}$ & $\begin{array}{l}\text { - Control of reckless prescription and } \\
\text { use of drugs (included antibiotics) } \\
\text { through electronic prescription } \\
\text { system. }\end{array}$ \\
\hline Use of anesthetics gas & $\begin{array}{l}\text { - Efforts regarding reduction of anesthetics gas } \\
\text { release. }\end{array}$ & $\begin{array}{l}\text { - No efforts are made towards this } \\
\text { environmental goal. }\end{array}$ \\
\hline $\begin{array}{l}\text { Use of products containing } \\
\text { Polyvinyl Chloride (PVC) and } \\
\text { phthalates }\end{array}$ & $\begin{array}{l}\text { - Reduction in use of products containing Polyvinyl } \\
\text { chloride and phthalates. } \\
\text { - Control of supplies and suppliers. }\end{array}$ & $\begin{array}{l}\text { - No efforts are made towards this } \\
\text { environmental goal. }\end{array}$ \\
\hline Disposable products & $\begin{array}{l}\text { - Efforts to slow down the use of disposable fabrics } \\
\text { - Working group producing information material } \\
\text { and other tools to encourage and facilitate the } \\
\text { reduction of disposable products use. }\end{array}$ & $\begin{array}{l}\text { - No efforts are made towards this } \\
\text { environmental goal. }\end{array}$ \\
\hline Waste & $\begin{array}{l}\text { - Classification of waste in } 25 \text { categories. } \\
\text { - Disposal of waste for recycling, bio-fuel, } \\
\text { production of thermal energy and use as raw } \\
\text { materials for new products. }\end{array}$ & $\begin{array}{l}\text { - Recycling. No available data as it is } \\
\text { collected by the municipality's } \\
\text { service. }\end{array}$ \\
\hline $\begin{array}{l}\text { Outdated good quality medical } \\
\text { equipment }\end{array}$ & $\begin{array}{l}\text { - It is checked, classified, restored and forwarded } \\
\text { for donation in countries in need, such as Africa } \\
\text { and refugee shelters. }\end{array}$ & $\begin{array}{l}\text { - Electronic and medical equipment } \\
\text { is not being donated; it is being } \\
\text { fixed. If not fixable it is recycled } \\
\text { based on instructions from local } \\
\text { authorities. }\end{array}$ \\
\hline
\end{tabular}


Table 5. Swedish- Greek hospital comparison

\begin{tabular}{lll}
\hline Sustainable development act & \multicolumn{1}{c}{ Swedish hospital } \\
\hline Patient and staff meals & $\bullet$ & $\begin{array}{l}\text { Efforts to reduce waste from patient and } \\
\text { personnel meals. } \\
\text { - }\end{array}$ \\
Energy consumption & Selection of organic food and local producers. \\
Archive Digitalization & $\begin{array}{l}\text { Installation of solar panels for energy } \\
\text { production to meet the needs of the building. }\end{array}$ \\
& $\begin{array}{l}\text { Digitalization of the cytological laboratory } \\
\text { and pathological clinic archive, saved space } \\
\text { and paper. }\end{array}$
\end{tabular}

\section{Greek hospital}

- No data or control on meals that are discarded.

- Meals are provided from catering company.

- Organic food is not preferred.

- Gas and electricity supplied by Public Power Corporation.

- Protocol department digitalization, offered reduces in space and paper use. No data available.

- Hospital information system gives access to patients' laboratory results, thus reduction in printing. No data available.

Environmental

Education
- Digital lessons of basic environmental education to all staff.

- Emphasis on social awareness and participation
- Environmental education and awareness of hospital's users through brochures has not been implemented.

- Education regarding medical waste handling to specific personnel, based on legislation.
Green procurementPublic procurement

Legislation compliance

- Compliance with national legislation and European regulations.

Climate change and adaptation
- Selection of products and goods produced locally in Region Stockholm.

- Accordance of Code of Conduct on human rights of Region Stockholm.

- Focus on setting sustainability requirements in public procurement
- Procurement department complies with environmental requirements only for cleaning products and not extended to other products.
- Compliance with European Union regulations, national legislation and ministerial decisions.
- Effective and systematic actions to adapt to the climate change.

- Climate commitment to increase preparedness in the face of continuous climate change and to reduce the negative situation in the long term.

\section{Discussion}

Both the bibliographic review and the conducted qualitative and quantitative surveys depict that there is plenty of room for improvement for both health units. Particularly, an opportunity for development in the Greek facility would be the designation of an environmental responsible, so that employees can be further committed to a greener hospital. The results from the quantitative research reveal that the personnel has individual ecological awareness to an extent; this component though, does not assist in achieving the various sustainability objectives. It is essential to establish a common vision or values, which will act as a common culture for all workers in order to accomplish common goals. An important move towards sustainability in GOHK would be the renewal of ISO 9001 certification, as well as the claim for ISO14001. This will offer a competitive advantage along with numerous 
opportunities for numerous sustainable practices across its functions range. In the Greek healthcare unit the environmental project was not incorporated into the decision-making process; this could be implemented in the future, so as to help the administration to head smoothly towards sustainability in combination with the implementation of the rest of its functions and procedures.

The targets set at the Swedish hospital for the year 2021 were to increase the number of care contacts per patient using telemedicine and remote care. Telemedicine is an area that requires further improvement. In the Greek hospital, the provision of remote healthcare and telemedicine is at a primary stage and the administration needs further caution. It appears though that GOHK's home care service, which has increased its number of recipients by $140 \%$ over past three years, has a positive outcome; those satisfactory results are immensely encouraging. Undeniably, this is an area which requires further progress and can create more positive results.

The aim of Karolinska is to create better mobility solutions and increase the share of public transport. The Greek facility aims to reduce the movements of workers by their own vehicles with the use of staff shuttle bus. Data from the survey revealed that the majority of respondents, i.e. $74.0 \%$, use their own car or motor for their everyday commute. This implies that action should be taken to decrease this rate; the suggested ways are related to the increasing shuttle bus service, expansion of the service network and ensuring special discounts on public transport for all users.

One area which GOHK could improve is the control of medicinal products; their use can be reduced by minimizing their prescription resulting to fewer burdens from their disposal to the environment. Moves such as the reduction of the use of anesthetic gases, the reduction of the use of PVC-containing products as well as the use of products such as disposable fabrics, give to the Swedish unit a priority to innovative sustainable ideas. Watching their accomplishment in Karolinska, these moves can be adopted from the Greek unit's administration as well.

In Karolinska, waste is classified and forwarded for recycling or as bio-fuel. However, according to the research there is a lot of opportunity for improvement especially regarding an increase in the quantities recycled. GOHK recycles waste; no data though is available, as it is collected from the municipal special trucks. The survey data revealed that $48 \%$ of respondents recycle fairly, to a greater extent paper $(50.3 \%)$; at rates of $22.3 \%$ and $21.2 \%$, batteries and plastic respectively. It is of special interest the result of the ages of those who recycle, as younger people aged 25-30 appear not to show similar empathy for recycling, since they recycle "a little" to "quite". Furthermore, there were some $26.9 \%$ who did not know at all or knew little $(27.9 \%)$ about the meaning of sustainable development. This implies that a significant proportion of employees is not sufficiently aware as far as the environmental protection is concerned and in particular from an economic, social and environmental point of view.

High-quality healthcare equipment is being replaced due to the rapid development of technology in healthcare; in the Swedish hospital's case, it is promoted for donation. The reuse of this obsolete equipment could constitute an example and be implemented to the Greek facility as well. One proposal for improvement in this area is to promote this equipment through non-governmental organizations to countries in need. This environmental movement would significantly reinforce hospital's social responsibility.

It was revealed that Karolinska could progress and possibly lessen further waste from patients' and workers' meals. Even more it could manage to control the suppliers of raw materials used for meal preparation. In the case of GOHK, the quantity of discarded meals is neither counted nor forwarded as compost for bio-fuel. The report, however, mentions the reopening of the kitchen area which will give a good opportunity to save economic and environmental costs by controlling the quantity of meals prepared; this may lead to reduction of meal dismissal. Moreover, another measure concerns the proper waste management of discarded meals that could be forwarded as bio-fuel. This process may constitute a source of revenue. Additionally, in case where the hospital itself selects the suppliers of raw materials used, it may act as a move towards a greener attitude.

In Greece, as a country with exceptional sunshine, the healthcare unit could follow the Swedish model and install solar panels. Energy produced could be utilized for electricity purposes, heating water, saving energy and shall reduce emissions of pollutants into the atmosphere.

There are numerous sectors in which the use of paper may lessen through digitization and this act could be extended to other departments in Karolinska. The operation of the new Hospital Information System and the implementation of the electronic patient file in GOHK may give the opportunity for improvement; thus will contribute positively to the achievement of green development.

Based on the bibliographic review at Karolinska, there is room for improvement in the field of environmental education. An increase to the number of trainees should be obtained. The mentality of respondents and employees 
was studied in the Greek hospital via research. It was revealed a mixed "green" behavior as the $63.5 \%$ of the respondents always turns off the lights or the air conditioning when leaving their workplace and the $48.1 \%$ recycles enough. On the other hand, just the $16.3 \%$ answered that knows the exact meaning of the term "sustainable development", while the $74.0 \%$ uses its own vehicle to move towards the hospital. Nevertheless, accomplishing sustainable development cannot be based solely on positive personal behaviors; compulsory environmental training should be implemented for all staff. In addition, creating a common "green" culture and sense of responsibility followed by everyone, mainly not only in the workplace, may create promising results towards environmental protection through economic and social aspects.

Swedish innovative ways regarding the environmental influence have been found through procurement and sustainable products and services. Moreover, the selection of local producers constitutes a solution towards this goal. The Swedish managers seem to have experienced issues due to the difficulty in monitoring the product track when suppliers buy from wholesalers. This area can be improved in the context of the implementation of green and public procurement. The Greek facility procurement department complies with environmental requirements for cleaning products, without being extended to different types of products. The survey pointed out that $77.9 \%$ of respondents were unaware of the term "green procurement", indicating a lack of information on the issue. The administration may succeed in this area by integrating several "green options" into procurement. Another opportunity is being introduced through the opening of the kitchen area and the selection of local producers and suppliers. The cooperation between the procurement department and the economic department can lead to greener public procurement.

\section{Conclusion}

The literature review and research highlighted the current situation regarding the achievement of sustainable development in two health services in Greece and Sweden. Sweden is a country strongly oriented to sustainable development. Karolinska Hospital is considered, by all accounts, an example for emulation regarding the ways of sustainability which are not integrated only in its budget, but also in the daily lives of all its users. This facility has likewise extended the range of feasible options across its scope of activities and has mostly positive results.

Greece is a country without a specific "green culture". Nevertheless, the study in General Oncology Hospital of Kifissia "Agioi Anargiroi" indicated that the situation is not as disappointing as one might expect. Obviously, the situation mentioned does not constitute a role model, but there are functions that take place and involve a sustainable aspect. There are indirect and direct environmentally friendly activities, but are not planned for the environment protection in economic and social terms; what has to be achieved is to make the "green" choices a conscious decision for all. The mentality of employees, its management and users' behavior should change and sustainable development should be a conscious choice rather than random result. The above demonstrates the differences between two health units in two European countries in terms of actions, programs, general awareness of sustainability and environmentally friendly practices in the healthcare sector. There is no doubt that Greece has to take "greener" steps in order for the healthcare sector to compete worthily with respective sectors in the international arena. This study was limited to one healthcare unit in Greece and another in Sweden. A study including other Greek hospitals would have particular research interest, so as to examine to what extent health sector adopts actions towards sustainability, to study separately both the private and public sector and to analyze the data collected. This study could then propose ways in which it would be practically possible for Greek healthcare facilities to integrate sustainable development into their operations, based on Greek reality and data.

\section{References}

Alipour, N., Sadegh Sangari, M., \& Nazari-Shirkouhi, S. (2019). Investigating Green Human Resource Practices in the Healthcare Sector: A Joint Application of Balanced Scorecard and SIR Method. 15th Iran International Industrial Engineering Conference (IIIEC), Yazd, Iran, 2019, pp. 283-288.

Bardwell, P. L. (2007). Factors of sustainability. Gauging environmental impact when deciding whether to build or renovate. Health Facilities Management, 20, 52.

Biondi, V., \& Frey, M. (1995). Participation in the EU Eco -Management and Audit Scheme: An analysis of small - and medium- sized enterprises in Italy. European Environment, 5, 128-133.

Burger, B., \& Newman, P. (2012). Curtin University of Technology, Perth, Western Australia. Hospitals and sustainability, 1-91. Retrieved January, 102020 from https://sustainability.curtin.edu.au/wpcontent/uploads/sites/31/2017/06/hospitals-sustainability.pdf

Carter, C. R., \& Carter, J. R. (1998). Interorganizational determinants of environmental purchasing: initial evidence from the consumer products industries. Decision Sciences, 29, 659-669. 
Chartier, Y., Emmanuel, J., Pieper, U., Prüss, A., Rushbrook, P., Stringer, R., ... Zghondi, S. (2014). Safe Management of Wastes from Healthcare activities. WHO, $2^{\text {nd }}$ edition, 1-329.

Cherian, J., \& Jacob, J. (2012). A study of Green HR practices and its effective implementation in the organization: a review. International Journal of Business and Management, 7, 25-33. https://doi.org/10.5539/ijbm.v7n21p25

Chiarini, A., \& Vagnoni, E. (2016). Environmental sustainability in European public healthcare: Could it just be a matter of leadership? Leadership in Health Services, 29(1), 2-8. https://doi.org/10.1108/LHS-10-2015-0035

Chiarini, A., Opoku, A., \& Vagnoni, E. (2017.) Public Healthcare practices and criteria for a sustainable procurement: A comparative study between UK and Italy. Journal of Cleaner Production, 1-27. https://doi.org/10.1016/j.jclepro.2017.06.027

Eckelman, M. J., \& Sherman, J. (2016). Environmental Impacts of the U.S. Health Care System and Effects on Public Health. PLoS ONE, 11, 1-14. https://doi.org/10.1371/journal.pone.0157014

Environment Science Center, Augsburg, Germany. (2003). Greener Hospitals; Improving Environmental Performance. 1-56. Retrieved September 21, 2019 from https://www.bms.com/assets/bms/us/enus/pdf/greener-hospitals.pdf

Finnveden, G., Johansson, J., Lind, P., \& Moberg, Å. (2005). Life cycle assessment of energy from solid wastepart 1: general methodology and results. Journal of Cleaner Production, 13(3), 213-229. https://doi.org/10.1016/j.jclepro.2004.02.023

Green Business Certification Inc. (2017). Leed in Motion: Europe. 1-22. Retrieved September 22, 2019 from www.gbci.org/articles/grid

Health Research \& Educational Trust. (2014). Environmental sustainability in hospitals: The value of efficiency, 1-34. Retrieved September 25, 2019 from http://www.hpoe.org/Reports-HPOE/ashe-sustainability-reportFINAL.pdf

Hoejmose, S. U., \& Adrien- Kirby, A. J. (2012). Socially and environmentally responsible procurement: A literature review and future research agenda of a managerial issue in the 21 st century. Journal of Purchasing and Supply Management, 18, 232-242. https://doi.org/10.1016/j.pursup.2012.06.002

Honkasalo, A. (1998). The EMAS scheme: a management tool and instrument of environmental policy. Journal of Cleaner Production, 6, 119-128. https://doi.org/10.1016/S0959-6526(97)00068-1

Introduction to ISO 14001:2015. (2015). International Organization for Standardization. Retrieved September 17, 2019 from www.iso.org

Iraldo, F., Testa, F., \& Frey, M. (2009). Is an environmental management system able to influence environmental and competitive performance? The case of the eco-management and audit scheme (EMAS) in the European Union. Journal of Cleaner Production, 17(16), 1444-1452.

Karolinska Universitetssjukjuset. (2017). Miljöredovisning 2017, 1-20, Retrieved November 18, 2019 from https://www.karolinska.se/om-oss/miljo-hallbarhet/

Karolinska Universitetssjukjuset. (2018). Miljöredovisning 2018, 1-24. Retrieved November 16, 2019 from https://www.karolinska.se/om-oss/miljo-hallbarhet/

Lado, A. A., \& Wilson, M. C. (1994). Human Resource Systems and Sustained Competitive Advantage: A Competency Based Perspective. Academy of Management Review, 19, 699-727. https://doi.org/10.5465/amr.1994.9412190216

Lizzi, G. D., Collazzo, R,. Capra, E., Lazzarini, R., \& Goi, D. (2017). The Environmental Management System in a Health Structure: The Case study of ORC-Aviano (Italy). The Open Waste Management Journal, 10, 1-12.

Malik, M. M., Abdallah, S., \& Hussain, M. (2015). Assessing supplier environmental performance: Applying analytical hierarchical process in the United Arab Emirates healthcare chain. Renewable and Sustainable Energy Reviews, 1-9. https://doi.org/10.1016/j.rser.2015.05.004

Mc Gain, F., \& Naylor, C. (2014). Environmental sustainability in hospitals - a systematic review and research agenda. Journal of Health Services Research \& Policy, O(0) 1-8. https://doi.org/10.1177/1355819614534836

Morrow, D., \& Rondinelli, D. (2002). Adopting Corporate Environmental Management Systems: Motivations and Results of ISO 14001 and EMAS Certification. European Management Journal, 20, 159-171. https://doi.org/10.1016/S0263-2373(02)00026-9 
Rathi, M., Wilburn, S., Welter, V., \& Dora, C. (2013). UN Initiative on Greening Procurement in the Health Sector from Products to Services, Landscape Analysis for the Technical Consultation. World Health Organization, $1-63$. https://apps.who.int/iris/bitstream/handle/10665/204120/9789241508667_eng.pdf.;jsessionid=67080EF654 10724CA0CC285703DC8F42? sequence $=1$

Seifert, C. (2018). The barriers for voluntary environmental management systems-the case of EMAS in hospitals. Sustainability, (10)1420, 1-9. https://doi.org/10.3390/su10051420

UK National Health Service, NHS Sustainable Development Unit. (2012). Goods and services carbon hotspots. 1-40. Retrieved April 8, 2020 from www.sduhealth.org.uk/documents/resources/Hotspot_full.pdf

United Nations. (1987). Our Common Future, Report of the World Commission on Environment and Development, $1-374$.

US Green Building Council Inc. (2010). LEED 2009 for Healthcare, 1-105. Retrieved October 5, 2019 from www.wbdg.org/ffc/va/sustainable-design/gp-checklist-leed-hc

Watts, N., Amann, M., Arnell, N., Ayeb-Karlsson, S., Belesova, K., Boykoff, M., ... Montgomery, H. (2019). The 2019 report of The Lancet Countdown on health and climate change: ensuring that the health of a child born today is not defined by a changing climate. Lancet, 394, 1836-78. https://doi.org/10.1016/S01406736(19)32596-6

Xuan, X. (2015). Effectiveness of indoor environment quality in LEED- certified healthcare settings. Indoor and Built Environment, O(0), 1-13.

Zouboulis, A. I., Peleka, E., \&. Triantafyllidis, K. (2015). Environmental Management Principles - Environmental Impact Assessment. In Green Chemistry and Technology in Sustainable Development (pp.145-184). Athens, Kallipos Publishing.

\section{Copyrights}

Copyright for this article is retained by the author(s), with first publication rights granted to the journal.

This is an open-access article distributed under the terms and conditions of the Creative Commons Attribution license (http://creativecommons.org/licenses/by/4.0/). 